\title{
¿Reina la reina? Mujeres en la cúspide del poder en los reinos hispánicos de la edad media (siglos VI-XIII)
}

\author{
deue el rey catar que aquella con qui en \\ casase aya ensi qua tro cosas. La pri mera que venga de \\ buen linaie. la .ij.que sea fermosa La .iij. que sea bien a- \\ costunbrada. la .iiij. que sea rica.
}

Partidas, 2, 6,1.

\author{
María Jesús Fuente \\ Universidad Carlos III de Madrid
}

\begin{abstract}
RESUMEN
Las cualidades de una mujer elegida como esposa de un rey quedan bien definidas en los códigos de leyes medievales; sin embargo, sus funciones no están explicitadas. Definir el papel de las reinas en los reinos hispánicos de la Edad Media es el objetivo de este artículo.

Tomando como base fuentes primarias y secundarias, se estudia la actuación de las reinas desde el siglo VI al XIII, en concreto algunas figuras representativas o de las que hay información en una documentación escasa y poco explícita. Se sigue su evolución en

tres grandes etapas: las reinas visigodas (siglos VI-VII), las reinas o condesas de los núcleos de resistencia del Norte peninsular (siglos VIII-X), y las reinas de los sigios XI al XIII en los ámbitos de Aragón-Cataluña y Castilla-León.
\end{abstract}

PALABRAS CLAVE: reinas, mujeres, poder monárquico.

\begin{abstract}
Although medieval legal codes spell out the qualifications of the king wife to be, they do not mention her role. To define her role is the goal of this article, which look at the queen in the hispanic kingdoms of the Middle Ages. Based on primary and secondary sources, it discusses the role of the queens from the VIth to the XIIIth centuries. The study looks first at the visigoth queens (VIth-VIIth centuries), then at the queens and countesses of the small kingdoms of Northern Spain (VIIIth-Xth centuries), and finally at the queens of Aragon-Cataluña and CastileLeon during the XIth, XIIth and XIIIth centuries.
\end{abstract}

KEYWORDS:

Queens, women, monarchical power. 
En las Siete Partidas y también en el Espéculo, los dos códigos de leyes del reinado de Alfonso $X$, se exponen las cualidades que un rey debía tener en cuenta al elegir esposa. Tras varios siglos de organización y de práctica de la monarquía se manifestaban explícitamente los requisitos que debería cumplir la elegida para madre de los hijos legítimos del rey, la futura reina. Sin embargo, aparte de las condiciones personales, nada se apuntaba acerca de lo que se esperaba que hiciera la reina, no se definía su papel. ¿No se consideraba importante atribuirle ninguna función? ¿No tenía derecho a intervenir en la vida política del reino?

\section{INTRODUCCIÓN: EL OFICIO DE REINA}

Preguntarse por el papel de las reinas no es algo nuevo. Desde las primeras décadas del siglo $X X$ aparecen referencias a las reinas y sus funciones en estudios de diversa indole, no faltando noticias en tratados de "clara orientación masculina" ${ }^{1}$. Había reinas con tal relevancia en la historia de sus países que no había otra opción más que incluirlas en las historias generales.

Desde la década de 1970, y coincidiendo con el interés por los estudios de género, el tema de la vida y el papel de las reinas ha atraído la atención de los estudiosos. Ya hace diez años, en 1993, Theresa M. Vann reunió un conjunto de artículos bajo el título Queens, Regents and Potentates, en el que se incluían estudios de reinas o mujeres de poder de varios ámbitos europeos ${ }^{2}$ : Inglaterra, Flandes y los reinos de la Península Ibérica. Diez años antes había publicado Pauline Stafford, Queens, Concubines and Dowagers ${ }^{3}$, excelente estudio sobre las mujeres en torno al rey, y después se publicó el conjunto de trabajos presentados en un congreso celebrado en Londres en 1995, bajo el título Queens and Queenship in Medieval Europe ${ }^{4}$, en el que se analizaron las obligaciones y funciones de las reinas en distintos ámbitos europeos. En estos ensayos se propone la idea de que las mujeres de la realeza ejercieron ciertos tipos de poder o de autoridad, probablemente más de lo comúnmente aceptado.

Conocer el poder, autoridad o influencia de las mujeres, ha hecho del estudio de las reinas un campo interesante, que se ha traducido en ensayos, monografías y biografías sobre reinas en distintos ámbitos europeos. Sobre las reinas de los reinos hispánicos medievales, se han publicado en los últimos años interesantes biografías (María de Molina, Catalina de Lancaster,

Lester K. Little y Barbara H. Rosenwein (eds.), La Edad Media a debate, Madrid, Akal, 2003, p. 339.

Th. M. Vann, Queens, Regents ans Potentates, Cambridge, Academia Press, 1993.

London and Washington, Leicester Univ. Press, 1983.

${ }^{4}$ Anne J. Duggan (ed.), Wcodbridge y Rochester, Boydell Press, 1997. 
Violante de $B a r)^{5}$, que han incrementado el panorama iniciado tiempo atrás (María de Luna, Juana Enriquez, Urraca de Castilla).

El tema, pues, no es un tema cerrado, por el contrario, requiere de estudios "regionales" para ofrecer una visión más esclarecedora. Entre los países necesitados de estudios de esta índole se encuentra España, donde hay una carencia evidente de monografias sobre el tema. De hecho en los estudios sobre reinas medievales se echan de menos ejemplos hispanos, tal como se ha puesto de manifiesto en algunas publicaciones?

En la línea de ampliación de los estudios sobre las reinas, este artículo se propone revisar su papel en los reinos hispánicos durante la Edad Media $^{8}$, y más en concreto la configuración de ese papel desde los primeros tiempos de la monarquía visigoda, hasta el momento de redacción del código de leyes arriba anotado. Para ello se hará un repaso general de las reinas de los reinos hispánicos, y se seleccionarán algunos ejemplos que pueden ser más significativos para exponer el papel de la reina.

Antes de plantear las preguntas iniciales, habría que recalcar el interés que el tema ha suscitado. Aún en tiempos en que las mujeres no eran objeto de estudios como tal, había libros sobre las reinas, biografías o florilegios, en las que solian aparecer como mujeres ejemplares y modelos a seguir. Desde que el estudio de las mujeres se convirtió en disciplina de gran interés, se ha afirmado que las mujeres en general o las reinas en particular "tenían mucha importancia» o «tenian mucho poder». Sin embargo, a esas afirmaciones habría que plantearle estas preguntas, ¿en qué se nota que eran tan importantes?, ¿cómo se mide su poder?, en última instancia, ¿qué fuerza tenía la reina?

El tema no es fácil, pues requeriría una reflexión previa sobre la idea de poder, y en concreto del poder ejercido por un monarca, diferente en distintas áreas geográficas. Pero aun conociendo los poderes del rey, la documentación no permite hacerse buena idea del papel ejercido por la reina, tal como se ha demostrado en estudios realizados para otros ámbitos europeos ${ }^{9}$. En

R. DEl Valle, Maria de Molina, Madrid, 2000; A. EchevaraiA, Catalina de Lancaster, Madrid, $2002 ; \mathrm{B}$. Bratsch-Prince, Violante de Bar, Madrid, 2002.

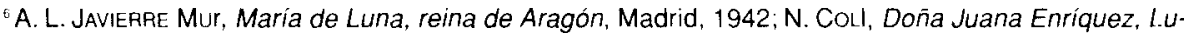
garteniente real en Cataluña, 1461-1468, Madrid, 1953; B. F. REll.t., The Kingdom of León-Castilla under Queen Urraca, Princeton, Princeton Univ. Press, 1982

P. STAFFord Queens, Concubines and Dowagers, London and Washington, Leicester Univ. Press, 1998 (paperback), primera ed. 1983. Se incluyen muchos eje nplos de diversas partes de Europa, excepto de la Península lbérica, de donde solo se apuntan las reinas mencionadas por Gregorio de Tours.

${ }^{8}$ Este tema se ha esbozado en mi libro Reinas medievales en los reinos hispánicos, Madrid, La estera. de los libros, 2003, del que se eliminó la parte más erudita, o de tesis, con el fin de hacerlo más accesible a un público no especialista. Sin embargo, realizada la investigación y habiendo utilizado tanto fuentes primarias como secundarias, este articulo pretende ser un complemeto de ese libro, y defender la tesis que no se expuso acerca del papel de las reinas en el espacio público, en concreto sus posibilidades de ejercer el poder. 
los códigos de leyes antes citados, tanto en las Partidas como en el Espécu10 , hay varios capítulos dedicados al rey y a su función en la monarquía ${ }^{10}$. Dos eran sus grandes poderes, el judicial y el gubernativo. El rey tenía potestad de gobernar la comunidad, mantener la paz, conservar la justicia, defender a la iglesia, proteger el territorio y guardar personas y bienes ${ }^{11}$. Nada especifican los códigos de leyes acerca de si esas prerrogativas del rey alcanzaban también a la reina. Habría que pensar que no, pues las menciones a las mujeres del rey, fueran esposas legitimas o concubinas, se encuentran en otros capítulos en los que simplemente se indica como se ha de guardar a la reina o a la mujer del rey. Las prerrogativas de un rey, o sus funciones, serían aplicables a las reinas cuando éstas tuvieran en sus manos el reino por ausencia de monarca varón.

Si los códigos de leyes no especifican ni las funciones ni el poder que ha de ejercer la reina consorte, hay que buscar indicios en otras fuentes. A falta de una teoria sobre las funciones de la reina, hay que acudir a la práctica, al estudio de la vida y de la actuación de estas reinas en el ámbito público. Para indagar en la vida de las reinas a lo largo de una etapa tan extensa de la historia, habría que hacer una selección de algunas figuras más representativas como ejemplos a estudiar, y ver si en su actuación aparecen los aspectos más significativos de la idea de poder de aquel tiempo, que podrían coincidir con la lista de potestades del rey antes apuntada. En realidad la selección viene dada por las propias fuentes, pues no son muchas las reinas de las que hay noticias.

Para estudiar las reinas de los reinos hispánicos vamos a considerar tres etapas. La primera la de las reinas de la monarquía visigoda, cuya influencia por sus pautas de actuación y código de leyes, el Liber ludiciorum, marcaria a las mujeres de las etapas siguientes. En segundo lugar las reinas o condesas de los núcleos de resistencia del Norte peninsular (reino astur y núcleos pirenaicos), como pioneras en los reinos y coronas que surgirían de los primitivos núcleos. Finalmente las reinas de la etapa de consolidación de los reinos de Castilla y Aragón (entre los siglos XI al XIII aproximadamente) con algunas figuras femeninas claramente remarcables, y en las que probablemente se fijó Alfonso X para redactar las características de una reina.

P. STAFFORD, Queens, Concubines and Dowagers

El Espéculo, Libro Segundo, y Las Partidas, Segunda partida.

P. A. Porras Arboleda, E. Ramirez Vaquero y F. Sabaté I Curull, La época medieval: administración y gobierno, Madrid, Istmo, 2003, pág. 57 y ss. 


\section{LAS REINAS VISIGODAS (SIGLOS VI-VII)}

En un estudio de las reinas en los reinos hispánicos medievales, las primeras a considerar son las esposas de los monarcas visigodos. Aunque pudiera ponerse en tela de juicio la necesidad de incluir a estas mujeres, son especialmente interesantes en la medida en que el Liber ludiciorum fue la ley utilizada durante siglos por todos los reinos peninsulares, y el comportamiento de estas reinas, junto a las normas de esta monarquía se copiarían durante siglos ¿Fue alguna de las reinas visigodas especialmente importante? ¿qué hicieron para significarse? ¿qué noticias hay sobre ellas en la documentación?

Las fuentes visigodas son muy poco explícitas respecto a las reinas. Una de las fuentes más importantes para el conocimiento de la etapa visigoda en general y de las mujeres de aquella época en particular, son las actas de los concilios de Toledo. Llama la atención que solo en tres concilios aparece el nombre de la reina, en el III (año 589) firma Baddo, “reina gloriosa ${ }^{12}$, en el XV (año 688) se nombra a Liuvigotona, y en el XVII (año 694) a Cixila (o Cixilo) ${ }^{13}$. Otra fuente importante, Las historias de los godos, vándalos y suevos de Isidoro de Sevilla, no llama por el nombre a ninguna de las reinas, refiriéndose a ellas simplemente como esposa, hija o madre de algún rey. Ni siquiera así menciona a Baddo, a la que Isidoro de Sevilla se refiere al hablar del Liuva II, «hijo de madre innoble»"

Esta «mujer innoble» fue, sin embargo, la única reina que aparece como firmante en un concilio. ¿Por qué Baddo fue la única reina firmante en un acta conciliar? Probablemente por la necesidad del rey Recaredo de presentarse en el concilio reconciliado con la Iglesia católica a la que reconocería como su religión desde ese preciso momento, exponiendo de forma solemne su conversión del arrianismo a la ortodoxia católica, y habiendo tomado como esposa legítima a una mujer que también había renunciado al arrianismo y declaraba solemnemente su adhesión a la fe católica. Algo similar haría más tarde Carlomagno, que antes de recibir la visita del papa en su corte, contrajo matrimonio con su concubina (799) a la que convirtió en su cuarta esposa legítima ${ }^{15}$.

"Yo Bado, reina gloriosa, firmé con mi mano y de todo corazón, esta fe que crei y admiti», Concilios visigóticos e hispano-romanos, ed. J. Vives, Barcelona, 1963, p. 116.

"Si alguna vez ocurriere que la gloriosa señora y reina Jixila, pasados los largos y felices años de nuestro serenisimo príncipe Egica, viviese religiosamente en el estado de viudez y tuviere del dicho rey dulcisimo descendencia, nadie intente, impulsado por alguna mordacidad envidiosa, o empujado por el estímulo del odio, o movido por inspiración y engaño del diablo, alzarse contra ellos". Concilios visigóticos e hispano-romanos, p. 533.

" C. Rodriguez Alonso, Las historias de los godos, vándalos y suevos de Isidoro de Sevilla, León, 1975, p. 269.

"P. STAFFORD, Queens, Concubines and Dowagers, pag. 61. 
Las otras dos reinas mencionadas en las actas conciliares, la "clementísima reina Liuvigotona", esposa del rey Ervigio, padres de la otra reina cita$\mathrm{da}$, la "gloriosa señora y reina Cixila" ${ }^{16}$, aparecen por encontrarse en el centro de graves problemas entre facciones. El rey Ervigio entregó a su hija Cixilo en matrimonio a su peor enemigo, Egica. Con ello trataba de poner a salvo la integridad de la familia real, en peligro al morir el monarca. Cixilo fue, así, la defensora de su familia, al tiempo que mujer manipulada. No hay noticias de que una vez convertida en reina, tuviera capacidad de maniobra política.

Es una fuente francesa, la Historia francorum de Gregorio de Tours, la que incluye citas más amplias de dos reinas visigodas, Clotilde, esposa de Amalarico, y Goswintha, esposa de Atanagildo y Leovigildo. Ambas estuvieron relacionadas con la monarquía franca. La primera al ser hija del rey Clodoveo, la segunda por ser la madre de Brunekhilda y Gailswintha, las princesas visigodas que se casaron con dos hermanos, Sigeberto de Austrasia y Chilperico de Neustria respectivamente ${ }^{17}$, y además abuela de Ingunda, la princesa franca que se casó con Hermenegildo.

De Clotilde cuenta Gregorio de Tours que era ferviente católica, y eso le valió los ultrajes de su marido que pretendía convertirla al arrianismo. De Goswintha cuenta sus problemas con Ingunda, al ser ésta católica, y no aceptar la imposición de su abuela que había proyectado convertirla al arrianismo. En ambos casos el autor, como católico y celoso hombre de iglesia, ensalza las figuras de las princesas católicas, y denuncia a las arrianas a quienes acusa de actos poco honorables. A Amalarico, el marido de Clotilde, de echarle estiércol cuando iba a misa; a Goswintha, de tirar de los pelos y arrastrar por el suelo a su nieta Ingunda. En ambos casos, especialmente en el segundo, el relato de Gregorio de Tours es tan exagerado que bien podría alimentar las críticas que se le han hecho de inventar un aparato dramático de gran efecto.

Gregorio de Tours distorsiona la realidad, hasta el punto de borrar la idea comúnmente aceptada en aquel tiempo de que una joven reina o una joven que entraba a formar parte de otra familia debía tener la misma religión que la familia de su esposo, de lo contrario no solo podian producirse fricciones, sino impedir la armonía que una reina había de traer a la familia ${ }^{18}$.

Aunque estos relatos no respondan a la realidad, y las figuras de estas reinas estén distorsionadas por el afán de defender el catolicismo propio de Gregorio de Tours, lo que parece evidente es que estas mujeres ejercían una influencia a través de su defensa de la religión. Esto se explica en una monarquía en la que se producía la identificación de lo religioso y lo político, y en

\footnotetext{
${ }^{16}$ Concilios visigóticos e hispano-romanos, pp. 465 y 533.

"En esta época el reino de los francos estaba dividido en Austrasia, Neustria y Borgoña

${ }^{18}$ P. STAFFord, Queens, Concubines and Dowagers, p. 121
} 
la que "parte de las órdenes emanadas de estas reinas dirigidas hacia lo religioso (apropiarse de reliquias, ordenar oraciones, presionar a los obispos, establecer dependencias y alianzas con comunidades monásticas rurales y urbanas), eran, sin duda, políticas " ${ }^{19}$. En efecto, las reinas podían tener gran influencia en los obispos, y eso ya las confería un poder significativo.

Uno de los momentos en los que la reina podría tener un protagonismo señalado era cuando se quedaba viuda. Sin embargo, la viudez no era siempre un tiempo feliz, pues se corría el riesgo de caer en medio de los intereses de las facciones. Su poder económico o su importancia social no estaban en relación directa con sus posibilidades de poder, puesto que cuanto mayor era su riqueza o influencia más era objeto de presiones para contraer un nuevo matrimonio o ingresar en un convento. Podría incluso decirse que a mayor poder económico correspondía una mayor debilidad. El futuro de una reina estaba en relación con los varones de la familia. Su posición se mantenía si tenía hijos varones y si éstos le permitían adquirir cierto poder ${ }^{20}$.

Hay que suponer, por otra parte, que la reina tendría ciertas responsabilidades en la familia real, como la distribución de comida, ropa y caridad, la educación de los jóvenes, o la recepción de obispos y visitantes. Como es difícil distinguir entre lo privado y lo público en el contexto de la corte real de aquel tiempo, podría pensarse que una reina tendría poder político al controlar el poder doméstico.

A falta de referencias extensas sobre la vida y actuación de estas reinas, se podría medir su posible poder o influencia comparándolas con sus coetáneas del reino merovingio, con las que estuvieron relacionadas y unidas, a veces, por lazos familiares. Se ha afirmado que las reinas merovingias tenían poder si podían controlar el aula regis, la corte ${ }^{21}$. Eso constituia «el auténtico poder y la influencia que concedía valor a la posición de una reina ${ }^{22}$. No hay noticia de que ninguna de las reinas visigodas tuviera ese control.

De las reinas visigodas mencionadas en la documentación citada, no se encuentra ninguna de la que se pueda afirmar con pruebas documentales que fuera mujer poderosa, excepto Goswintha. Ella fue la única verdaderamente manipuladora e influyente. Cixilo fue, por el contrario, una reina manipulada, precisamente como consecuencia de la lucha de facciones que la utilizaron. Finalmente Baddo no tuvo ninguna influencia o poder, pero fue necesaria.

\footnotetext{
"Baltilde "utilizó la piedad como medio de asegurarse su posición personal y como instrumento político", L. K. Little y B. H. Rosenwein (eds.), La Edad Media a debate, p. 379.

L. K. LitTle y B. H. RosenweIn (eds.), La Edad Media a debate, p. 355

El poder de las reinas francas Brunilda y Baltilde se demuestra al controlar la primera la intendencia del aula regis, y el palatium la segunda la red de amistades que giraba en torno a la corte.

2 L. K. LitTLE y B. H. RosenweIN (eds.), La Edad Media a debate, p. 376.
} 
En resumen, habría que señalar que las reinas visigodas fueron mujeres necesarias y utilizadas; no se puede decir que las mujeres mandaban en este reino. Como sus contemporáneas merovingias, ninguna reina podía reinar por derecho propio. Ser la compañera de cama del rey, incluso ser la madre de sus hijos, de ningún modo equivalía a ser reina. Tendrían mucha importancia, y se las calificaba de señora, gloriosa o clementísima, pero se las manipulaba como simples fichas que se utilizaban en los momentos oportunos.

\section{LAS REINAS O CONDESAS DE LOS NÚCLEOS DE RESIS- TENCIA EN EL NORTE PENINSULAR (SIGLOS VIII-X)}

Al formarse los núcleos de resistencia en el Norte peninsular tras la caída del reino visigodo, se observa la presencia activa de reinas o condesas en los núcleos de Asturias, Pamplona, Aragón o Barcelona. No es fácil, sin embargo, encontrar ejemplos que permitan conocer la evolución en cada uno de esos núcleos entre los siglos VIII al X. La falta de datos lleva a seleccionar algunos ejemplos, con los que se puede construir solo un panorama parcial: una mujer poderosa o influyente, en un espacio y un tiempo concretos.

El primero de los ejemplos es el de Ermesinda de Asturias (siglo VIII). Hija de Pelayo, y esposa de Alfonso I, el hijo del duque visigodo de Cantabria, la figura de Ermesinda se enmarca en un momento en que las mujeres se consideraban transmisoras de la herencia, de manera que el poder de Pelayo pasaría a Alfonso a través de Ermesinda. Aparte de esta circunstancia, no hay detalles en la documentación que permitan pensar que esta mujer tuviera un papel relevante en el reino astur que se creaba en aquel momento. Las crónicas mencionan que el matrimonio de Ermesinda con Alfonso se realizó «Pelagio praecipiente», es decir, por personal deseo y expreso mandato del rey Pelayo, lo que simplemente puede indicar que su padre la consideraba pieza clave para transmitir el poder de la forma que a él le parecía más conveniente.

¿En qué consistía, pues, el poder de la matrilinealidad? No parece ir más allá de un simple paso de la herencia a través de una figura femenina, pues ninguna de las mujeres del reino astur aparece en las crónicas con un papel diferente a ese. Solo Adosinda, la hija de Ermesinda y Pelayo, parece haber estado involucrada en la polémica religiosa del adopcionismo, por referencias que existen en cartas de los obispos implicados en esa querella religiosa. Es, pues, en un asunto religioso en el que se puede ver la intervención de una mujer del grupo dirigente.

No fue mayor el papel de otras reinas de los siglos VIII y IX, y ha de llegar el siglo $X$ para encontrar una mujer de la realeza involucrada de forma diferente. Se trata de la princesa Elvira, hija de Ramiro II de León. Monja en el 
Monasterio de San Salvador, que su padre había fundado para ella ${ }^{23}$, esta princesa ocupó el puesto de regente como consecuencia de la repentina desaparición de su hermano, el rey Sancho el Craso, en el año 966. Quedaba como heredero un niño de cinco años, llamado Ramiro, a quien la princesa Elvira se apresuró a hacer coronar rey. Ella fue la auténtica reina de León en los años de la minoria de edad del nuevo monarca Ramiro III (966-984). Ella es la que aparece tomando decisiones como firmar treguas con el califa cordobés, hacer frente a los ataques de los normandos o acudir al asedio de la fortaleza de Gormaz.

Elvira hacía gala de las dotes de su abuela Toda, la reina de Pamplona que en la primera mitad del siglo intervino en los reinados de su marido, de su hijo y de su nieto, especialmente en los de estos dos últimos, al tener la oportunidad de ser regente de su hijo García I Sánchez (925-970), y querer ayudar a su nieto, Sancho el Craso (956-958/ 960-966) cuando fue desposeído de su reino de León. Toda se hizo cargo del reino de Pamplona, y llevó todos los asuntos que a un monarca pertenecían, y así se la ve al lado del rey de León, Ramiro II, y del conde de Castilla, Fernán González, cuando el primero decidió enfrentarse a los musulmanes en la batalla de Simancas (939). Años después acompañaria a su nieto Sancho al médico cordobés Hasday ben Shuprut, para buscar cura a su obesidad, parte de su estrategia para recuperar el trono perdido de León, que negoció en la entrevista que mantuvo con el propio califa Abd al-Rahman III.

Toda reinó conjuntamente con su hijo, tal como demuestran muchas cartas del reino de Pamplona y del condado de Aragón que mencionan a García Sánchez y a su madre juntamente. Una fuente árabe (Ibn Hayyan) relata que los árabes vieron a Toda como la verdadera gobernante de Pamplona, responsable de las decisiones diplomáticas, políticas y militares del reino.

Pero Toda fue una excepción, y no la norma. Sus hijas o las mujeres de su hijo no llegaron a tener un papel semejante. La primera esposa de su hijo fue Andregoto Galíndez, la hija del conde de Aragón, Galindo II, que llevó el condado al matrimonio. Andregoto no solo no reinó, sino que fue repudiada por el rey, a pesar de que mantuvo su derecho de transmisión del condado de Aragón al hijo que habían tenido conjuntamente y de ser considerada como reina por los habitantes de la zona donde ella residía.

Las reinas del territorio pirenaico occidental disfrutaron de cierto poder, o al menos gozaron de un papel público pronunciado en el reino de Pamplo$\mathrm{na}^{24}$. Fue ese papel el que pudieron copiar las reinas de León, desde el momento en que se produjeron las conexiones familiares a través de los

Este es el primer monasterio concedido a la hija de un rey, y va a inaugurar una institución fundamental para las hijas de los reyes: el infantazgo. A partir de esta primera fundación, las infantas tendrian los monasterios del reino, y adquiririan un poder considerable.

${ }^{24}$ J. C. Parsons (ed.), Medieval Queenship, New York, St. Martin's Press, 1998. p. 87 y ss. 
matrimonios de uno y otro reino. Las relaciones entre reinos de una parte y otra de la franja Norte peninsular promoverían influencias en la forma de actuación de las reinas. Si en un principio en ambas zonas existían pervivencias matrilineales, pronto desaparecerian en ambos lados, pero quizás más tempranamente en la parte Occidental. Las reinas de la monarquía astur, luego reino de León, se vieron pronto oscurecidas, y difícilmente se las encuentra actuando en aspectos importantes del reino. No fue hasta la segunda mitad del siglo $X$, cuando entran en escena mujeres como la regente $D .{ }^{a}$ Elvira y su cuñada D. $\stackrel{\text { a }}{ }$ Teresa.

El reino de León, como su predecesor el reino de Asturias, se sentía heredero de la tradición gótica ${ }^{25}$. Las reinas de León estuvieron condicionadas por las leyes visigóticas, pues fue el Fuero Juzgo la ley que se siguió en estos reinos durante siglos, unida al derecho consuetudinario que se iba gestando paralelamente. En algún caso no les faltaría la influencia navarra, que podría haber sido más liberalizadora del papel de la reina, o al menos así se presenta en algunos aspectos. En el reino de León, como en el de Pamplona, el rey y la reina aparecen juntos en las donaciones, siguiendo la ley visigoda, que exigía el consentimiento de ambos esposos en la alienación de sus posesiones matrimoniales. Sin embargo, en muchos documentos la reina aparecía como una simple testigo. Su papel estaba muy limitado, y en la mayoría de los casos era la pieza del tablero que otros movian en su beneficio, no tenía libertad de movimientos.

Los aspectos en los que intervenían las reinas o condesas parece que trascendían el ámbito meramente privado, aunque, como ocurría en tiempos de las monarquías visigoda y merovingia, todavía era difícil diferenciar lo público y lo privado. Tener poder en la esfera privada podía significar tener un poder enorme. Un buen ejemplo se encuentra en tiempos carolingios, cuando las reinas tenían acceso al palacio y al tesoro. En la Capitulare de Villis, Carlomagno declaró que lo que la reina ordenara a los jueces, ministros, senescales y escanciadores, debía ejecutarse al pie de la letra. Se podría considerar un poder enorme en esa época en la que difícilmente se distinguía entre el poder privado y público de un gobernante ${ }^{26}$. Hincmar de Reims expuso, dos generaciones después, que la reina estaba a cargo del tesoro real junto al chambelán, puesto que el rey no podía verse implicado en tales trivialidades domésticas ${ }^{27}$.

25 J. C. Parsons (ed.), Medieval Queenship, p. 90.

L. K. LitTLE y B. H. Rosenwein (eds.), La Edad Media a debate, pág. 395.

P. StafFord, Queens, Concubines and Dowagers, pag. 99. En el 882 Hincmar de Reims escribió un tratado De Ordine Palatii para la instrucción del joven rey Carloman. Se basó en una obra anterior sobre el palacio de Carlomagno, escrita por Adalhard hacia el 814. Adaihard dividia el gobierno en dos: regir el reino y ordenar el palacio, colocando a los dos a un mismo nivel. La organización del palacio estaba reservado a la reina y a los grandes oficiales. Eran responsabilidades de ella la organización de la casa, el mantenimiento de la dignidad real y la provision anual de regalos para los altos oficiales. 
Sin embargo, como ocurría con sus antecesoras merovingias, de las reinas del territorio peninsular no hay documentación suficiente que permita afirmar que tenían un poder semejante al de sus coetáneas del otro lado del Pirineo.

\section{LAS REINAS DE LOS SIGLOS XIAL XIII}

Varias son las mujeres en la cúspide que podrían ilustrar el papel de las reinas durante estos siglos. Su poder o influencia en la vida política del reino vino condicionada en buena medida por las leyes que las afectaban sobre la transmisión del poder o la habilidad de las mujeres para mantenerlo en sus manos. Aunque es difícil elegir ejemplos, vamos a seleccionar varios, siguiendo simplemente el criterio de considerar las características de los dos grandes espacios políticos, el de los reinos que configurarían la corona de Castilla, y el de los reinos que formaron la corona de Aragón.

\subsection{Las condesas catalanas y las reinas de Aragón}

Los espacios políticos del Nordeste peninsular tuvieron leyes distintas en relación a las mujeres de las familias dominantes. En el espacio aragonés las hijas de los condes primero, y las de los reyes luego vieron limitado su poder por la ley que reducía su intervención en el reino a ser las portadoras del poder, pero no sus detentadoras. Ya en el siglo X, la hija del conde de Aragón, Andregoto Galíndez, con derechos al condado superiores a los de sus siete hermanos, solo tuvo la posibilidad de transmitir el condado a su hijo, Sancho Garcés II Abarca, pero no de ejercerlo ella ${ }^{28}$. Una mujer tenía el derecho al dominio del regnum, pero no podía ejercer la potestas, que había de poner en manos de un marido o un hijo.

Mientras que en Aragón se imponía esta norma restrictiva, en los condados catalanes las mujeres no estaban sujetas a leyes tales, de manera que antes de que se produjera el pacto con Aragón (1137), las condesas de Cataluña pudieron ejercer el poder. Buen ejemplo de ello fue Ermesinda de Carcasona, la esposa del conde Ramón Borrell I (992-1018), que ejerció como condesa al morir su marido y dejar a un niño pequeño, Berenguer Ramón I (1018-1035), y después al morir éste y dejar un hijo, Ramón Berenguer I (1035-1076) de cuya minoría también se encargó. La condesa Ermesinda fue una de esas madres dominantes y abuelas octogenarias que se inmiscuyeron en la vida de su hijo y de su nieto, tratando de imponer las normas que ella consideraba coherentes en el condado de Cataluña. Su actuación habria que considerarla, pues, en el margen entre lo privado y lo público, dadas las escasas diferencias entre lo uno y lo otro en la época que le

${ }^{26}$ M. J. FuEntE, Reinas medievales en los reinos hispánicos, p. 92 y ss, 
tocó vivir. En cualquier caso, el hecho de ser mujer no significó una merma de su capacidad para intervenir en los asuntos del condado.

Lo mismo le ocurriría a una de las esposas de su nieto, Almodis de la Marca, mujer extraordinaria y ejemplo curioso de la manipulación que padecían las mujeres de los grupos sociales poderosos, así como de sus posibilidades para manipular a otros. Varios son los aspectos en los que se muestra su faceta de mujer poderosa: consiguió un importante patrimonio a través de la dote ofrecida por su marido el conde, así como el cobro de parias que también le concedió su esposo. Ese patrimonio la convirtió en gran señora feudal. Como tal señora feudal y como condesa hace su aparición al lado del conde en muchos de los documentos del condado ${ }^{29}$, mostrando su capacidad para actuar en contratos de compraventa, donaciones, juicios, etc. al mismo nivel que su esposo el conde. Sin embargo, de todas sus actuaciones quizás la más llamativa sea su intervención en el inicio de la compilación de los Usatges de Cataluña, las normas que se aplicarian en ese territorio en sustitución del derecho germánico y romano llegado hasta entonces. No lo hizo sin antes estudiar la ley existente, el Liber ludiciorum, que quiso conocer con el fin de considerar su posible transformación.

La participación activa en el poder de estas dos mujeres que habían salido de los grupos nobiliarios de la antigua Septimania, no tuvo continuación en los siglos posteriores. No se puede señalar, hasta muchos siglos después, a ninguna mujer de la "talla política" de una Ermesinda o una Almodis. Posiblemente sus sucesoras no tuvieron las oportunidades que se les presentaron a estas dos condesas.

Tres fueron las circunstancias que permitieron a Ermesinda intervenir en los asuntos del condado: en primer lugar la ausencia de varón al frente del poder del condado, al morir primero su marido y luego su hijo; en segundo lugar la existencia de unas leyes que no impedían el acceso al poder de las mujeres; y finalmente su propio carácter. Almodis se benefició de estas dos últimas circunstancias, pero habría que añadirle una tercera: su interés por controlar el poder para pasarlo a sus hijos, desposeyendo al heredero legítimo, que era el primogénito de Ramón Berenguer I, habido con su primera esposa.

Sin estas circunstancias $u$ oportunidades, otras condesas de Cataluña no llegaron a ser dirigentes destacadas, ni siquiera mujeres bien conocidas, aunque las leyes no les fueran adversas. Pronto, con el pacto entre Ramiro II de Aragón y Ramón Berenguer IV de Cataluña, las leyes de Aragón se aplicarían a las reinas condesas, y difícilmente podían mandar, dadas las restricciones de las leyes aragonesas antes señaladas que prohibían a las mujeres ejercer la potestas. 
Las posibilidades de poder de una reina de Aragón, establecidas de tiempo atrás, se pusieron de manifiesto al ser designada heredera del trono Petronila de Aragón, la hija que el monje Ramiro II había tenido para conseguir que el reino no atravesara una nueva crisis como la que había sobrevenido al morir su hermano Alfonso I el batallador (1104-1134). Petronila de Aragón fue esencial para el traspaso de la potestas del reino de Aragón, que recibió de su padre y cedió a su marido, el conde de Barcelona. Ramiro II no podía dejar el poder en manos del conde de Barcelona, o de cualquier otro mandatario, sin la intervención de la legítima heredera del reino. Esta mujer recibía el poder como un sirviente que toma en sus manos un objeto valioso, $y$ ha de pasarlo intacto a las manos del señor, para que éste lo pueda disfrutar. Petronila servía así al reino, haciendo entrega de la potestas para que la disfrutara su futuro marido, y a la muerte de éste, el hijo de ambos. Petronila es posiblemente uno de los mejores ejemplos de manipulación de la mujer en la cúspide, a quien se necesita, se utiliza, pero que no tiene otro poder que el de aparecer en los documentos públicos, firmando lo que otros han escrito para ella, y que se limita a rubricar.

Es difícil imaginar qué hubiera ocurrido en el caso de que Petronila hubiera sido una mujer con ansias de poder, pues su participación en los asuntos del reino fue escasa o nula, bien es verdad que era un niña cuando su padre se retiró de nuevo al convento, y pasó su niñez bajo la protección de su segundo marido. Éste fue un gobernante que no la necesitó, de la misma manera que tampoco precisó de su ayuda su hijo y heredero Alfonso II. Petronila, que al título de reina de Aragón unía el de condesa de Cataluña por su esposo, nunca tuvo el poder ni la influencia que tuvieron las antepasadas de su esposo antes citadas, Ermesinda de Carcasona y Almodis de la Marca, aunque Petronila era de estirpe real, aportaba un trono, y su matrimonio iniciaba una unión importantísima en la historia de España, la corona de Aragón. El poder que transmitia Petronila era mucho mayor que el de su famosa prima, Leonor de Aquitania, pero nunca llegó a ejercerlo, ni por derecho ni por deseo, y eso no la ha permitido alcanzar la fama de su prima ${ }^{30}$.

Tras Petronila, las reinas de Aragón no desempeñaron papeles influyentes durante estos siglos de la Plena Edad Media. Las esposas de los monarcas de Aragón y condes de Barcelona, se limitaron a ser las madres de los hijos legítimos del rey, y no sería hasta mucho tiempo después, hasta finales del siglo XIV, cuando aparezcan figuras femeninas destacables entre las reinas de la corona de Aragón.

30 Árbol genealógico de Petronila de Aragón, que muestra su parentesco con Leonor de Aquitania: la madre de Petronila era hermana del padre de Leonor, y tenian un abuelo común, Guillermo de Aquitania.

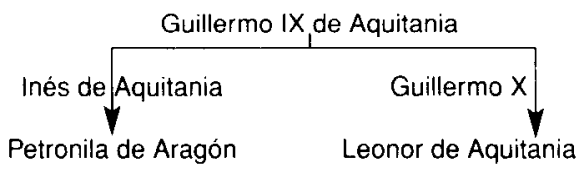




\subsection{Reinas de León y Castilla}

De todas las reinas medievales de los reinos hispánicos hay una especialmente importante: Doña Urraca, la heredera de los reinos de León y de Castilla al fallecer su padre Alfonso VI en 1109. La historia de Urraca desde el momento en fue reina es la de una mujer poderosa que por si misma tomó las decisiones más acordes con sus intereses o forma de pensar. Urraca fue, pues, mujer de gran poder, ¿en qué se manifestó ese poder?

Habría que iniciar el estudio de la fuerza de Urraca a partir del momento de la muerte de su padre. Unica heredera legitima del monarca, Urraca no esperaba acceder a una potestad que estaba reservada para los hijos varones del rey, en tanto que su padre continuara intentando tener heredero varón. Urraca llegó a ser reina por la conjunción de circunstancias favorables. En primer lugar porque de las siete mujeres conocidas en la vida de su padre, solo una le dio un heredero varón. En segundo lugar por la desaparición de éste antes de morir su padre. Y en tercer lugar por no tener marido, pues el primero, Raimundo de Borgoña, murió antes que su padre, y el segundo, Alfonso I de Aragón, dejó de serlo al anular la Iglesia su matrimonio.

Mientras vivió su primer esposo, Urraca, aunque legítima heredera durante mucho tiempo, no se molestó en prepararse para reinar; su esposo, Raimundo de Borgoña, estaba esperando la corona para ser él quien verdaderamente ejerciera el poder. En un breve espacio de tiempo, Urraca perdió a los tres hombres que la ascenderian al trono, en 1107 murió su marido, en 1108 su hermano y en 1109 su padre. La muerte inesperada de los dos primeros le abrió el camino del ejercicio del poder. Sin embargo, no lo hubiera ejercido de igual manera si el matrimonio con el hombre que le había elegido su padre, Alfonso I de Aragón, no se hubiera anulado. Hubo necesidad, pues, de una tercera circunstancia, el desastre de su segundo matrimonio, para que Urraca actuara como reina de Castilla y de León.

Sin embargo, la entrada de Urraca en la escena política se habia iniciado, aunque tímidamente, a partir de la muerte de su esposo, pues tuvo que intervenir en asuntos concernientes a las tierras del Noroeste peninsular dominadas por su marido. Una vez enterrado el cuerpo de Raimundo en Santiago de Compostela, ella permanecería en Galicia para hacerse con el control de esa tierra. En ese mismo año de la muerte de su marido, Urraca firma su primer diploma en solitario, con el título de "señora de toda Galicia", y un mes después en otro documento se autodenomina "emperatriz de toda Galicia»" ${ }^{31}$.

Poca era su experiencia cuando comenzó a reinar. El comienzo no fue fácil. El primer año de reinado estuvo marcado por el problema que surgió al

"Totius Gallecie domina" es el título con el que aparece Urraca en un diploma del Archivo Catedral de Santiago, y "tocius Gallecie emperatrix" en un documento del Archivo Catedral de Lugo, citados por B. F. REILLY, The Kingdom of León-Castilia under Queen Urraca. pp. 48 y 50. 
contraer matrimonio con Alfonso el batallador. Si su padre le habia considerado candidato apropiado, no pensaban lo mismo otros nobles del reino. El mayor opositor a ese matrimonio fue el conde de Portugal, el cuñado de la reina, que con esta boda veía desbaratadas finalmente sus esperanzas de hacerse con el reino. Otros nobles gallegos y leoneses también se opusieron. Probablemente ninguno hubiera tenido éxito si no hubiera estado la Iglesia en ese mismo lado. En efecto, muchos obispos se oponían a ese matrimonio. Fueron éstos los que encontraron la posible fórmula para hacer fracasar el enlace: denunciaron el matrimonio por consanguinidad, ya que los contrayentes compartian el mismo bisabuelo, Sancho III el Mayor de Navarra.

Urraca no hacía mal matrimonio al casarse con el batallador. Las cartas de arras que se intercambiaron otorgaban a Urraca la potestas del reino de Aragón, y durante el tiempo que duró el matrimonio, Urraca participó por derecho propio en decisiones del reino aragonés. Un ejemplo es la negociación que Urraca realizó con uno de los reyes de taifas, de quien consiguió una importante cantidad de dinero a cambio de dejar libres a algunos rehenes $^{32}$. Por el acuerdo matrimonial, uno y otro tenían completo derecho a intervenir en el reino del cónyuge.

Pero Urraca tuvo el problema del enfrentamiento de parte de la nobleza y del clerc de sus reinos a ese matrimonio, lo que significaba, por otra parte, que su autoridad moral y legal como legítima heredera no iba acompañada del apoyo militar y económico que requería tal designación. Sin embargo, Urraca dio muestras de tener las dotes políticas para gobernar un reino: supo pactar, manipular y acudir a donde consideraba que se la necesitaba.

En su actuación diplomática demostró casi siempre ser más astuta y hábil que sus adversarios ${ }^{33}$. Supo pactar con quien consideraba oportuno para recuperar el poder perdido, o para no perderlo en caso de que viera peligro. Supo acudir allí donde veía que se necesitaba su intervención y presencia, para que no olvidaran que ella era la reina, aunque esto le acarreara problemas graves, como el que padeció en Santiago de Compostela, cuando estuvo a punto de morir junto al Obispo en la torre de la catedral, perseguidos por los burgueses de Santiago, enfrentados con su señor el Obispo ${ }^{34}$. Supo, en resumen, defenderse y manipular en ese mundo masculino de guerreros, nobles y clérigos poderosos, y conseguir lo que quería.

Precisamente para frenar la ambición de la nobleza y los posibles enfrentamientos entre facciones que se había producido en décadas precedentes y seguían produciéndose, tomó la medida de asociar a su hijo. Alfonso VII, al trono, y asi dejar asegurada la sucesión, al tiempo que frenaba la ambición

J. A. LEMA PUEYo, Instituciones politicas del reinado de Alfonso / el Batallador, rey de Aragón y Pamplona, Bilbao, Servicio Editorial Univ. Pais vasco, 1997, p. 58.

B. F. Rell.ty, The Kingdom of Leon-Castilla under Queen Urraca. p. 78.

Historia Compostelana. 
de los que utilizaban a su hijo contra ella. Mantuvo las buenas relaciones con su hijo por contener a la nobleza y lograr la paz en el reino. En realidad Urraca utilizó a sus hijos como piezas en el juego político del reino. En 1117, cuando asoció al trono a su hijo Alfonso, que debía tener aproximadamente doce años, fue también cuando comenzó a aparecer en la documentación su otra hija, la princesa Sancha, cuyas propiedades del infantazgo controlaba la reina, y fue cediendo a su hija en fases sucesivas.

La reina Urraca, sin embargo, podría considerarse la excepción que confirma la regla de la escasa intervención política de las mujeres en estos siglos medievales. Se la ha calificado de "reina indomable», y se ha dicho de ella que fue "única". En efecto lo fue en la medida que gobernó por derecho propio en uno de los más importantes reinos de Europa Occidental en aquel tiempo.

En comparación con reinas bien conocidas de su tiempo, Urraca fue mucho más poderosa. B. F. Reilly la compara con Blanca de Castilla o Leonor de Aquitania, y dice de éstas que no fueron más que la reina madre en el caso de Blanca, y "la más capaz de las intrigantes" en el caso de Leonor ${ }^{35}$, mientras Urraca fue una auténtica gobernante.

La comparación de Urraca con otras reinas castellano-leonesas de los siglos XI-XIII también inclina la balanza del lado de Urraca, pues no hubo ninguna otra mujer que tuviera las posibilidades de poder que tuvo esta reina. Otras mujeres tendrian cualidades, serían influyentes, pero ninguna tuvo el trono vacante como lo tuvo Urraca. Su abuela Sancha de León, su tía Urraca de Zamora, su hija Sancha, fueron mujeres influyentes en las cortes de sus maridos y hermanos, pero al haber un gobernante, el papel que a ellas les correspondía era el de mediadoras. Ni siquiera la hija de la famosa Leonor de Aquitania, Leonor de Plantagenet, casada con Alfonso VIII tuvo un papel relevante en la corte, y algunas de las intrigas que favorecieron a la familia fueron tramadas por su madre, Leonor, o por su hija, Blanca de CastiIla, reina de Francia.

\section{PARA CONCLUIR: EL PODER DE LA REINA}

"...como todos los concejos de Extremadura enviassen cavalleros e omnes bonos de los pueblos con quien enviaron pedir merced a la reina doña Yolant, mi mugier, que nos rogasse por ellos, que les tolliesemos, algunos agravarmientos que dizien que avien ... nos por ruego de la reyna ... fazemos estas mercedes" ${ }^{36}$.

35 B. F. REILLY, The Kingdom of León-Castilla under Queen Urraca. p. 352.

${ }^{3}$ J. VAldeón, Alfonso X. La forja de la España Moderna, Madrid, Temas de Hoy, 2003, p. 133. 
Si en el código de las Partidas no se legislaba sobre las funciones o el poder de la reina, y simplemente se apuntaban los méritos que ésta habia de reunir, en la propia práctica del reinado de Alfonso $X$ se pueden encontrar manifestaciones de la función de la reina. Su esposa, la reina Violante, actuaba como intermediaria o mediadora, como «Esther ${ }^{37}$. ¿Esto significaba que la reina tenía poder?

A la hora de llegar a alguna conclusión sobre el poder de la reina, de entender su papel en los reinos medievales hispánicos, de deducir si su actuación era realmente poder, habría que plantearse qué se entiende por poder. Ante la complejidad del tema, vamos a limitarnos a mirar la distinción entre poder y autoridad. La diferencia esencial entre uno y otra radica en que el primero es "un poder socialmente reconocido", y la segunda "un saber socialmente reconocido". Mientras que el poder es delegable, la autoridad implica una capacidad innata; el primero, pues, se puede adquirir de otro, la segunda significa el desarrollo de capacidades personales ${ }^{38}$. Las manifestaciones de poder se identifican generalmente con la capacidad de ejercicio del mando político, y el centro de la política es conseguir el poder. "La operación política por excelencia es la mediación... la calidad de la mediación da la calidad de la política" ${ }^{39}$. Siguiendo este modelo teórico habría que preguntarse si las reinas estudiadas tuvieron poder o autoridad.

Los ejemplos de las reinas seleccionadas no permiten llegar a una conclusión uniforme. El poder o "potestas", con sus características de recibido, delegable y sin necesidad de capacidades personales, se encuentra en las reinas de Aragón. Un buen ejemplo sería la reina Petronila, que recibió el reino de manos de su padre, y lo delegó en su esposo. Ella era el sujeto de poder. Pero tener el poder no la daba acceso al gobierno del reino. Le faltaba la autoridad. Sin embargo, es dificil afirmar que no tuviera capacidad para ejercerla, pues su ausencia en las decisiones del reino se debía a las normas de Aragón, que excluían a las mujeres de la intervención en los asuntos de gobierno.

El ejemplo contrario podría personalizarse en Almodis de la Marca, quien no recibió poder político ni lo delegó, pues accedió al condado al casarse con el conde de Barcelona. Sin embargo, en su actuación al lado de su marido dio muestras de una capacidad personal para ejercer la autoridad. Como se afirmó antes no se limitó a ser mediadora, sino que intervino en muchos otros aspectos del condado. De hecho, aunque no tenía el poder suficiente como para pasarlo a sus descendientes, consiguió a través de sus dotes personales que sus hijos fueran los receptores de la "potestas", en

\footnotetext{
'L.L. HunEyCUt, "Intercession and the High-Medieval Queen:The Esther Topos", Power of the Weak. Studies on Medieval Women. Urbana \& Chicago, Univ. of Illinois Press, 1995, pp. 126-146

${ }^{38}$ A. HERnando, "Poder y autoridad de las mujeres. La relación como base de la identidad femenina", Las mujeres y el poder. Representaciones y prácticas de vida, Madrid, AEIHM, 2000, p. 23.

"L. MURARo, "Autoridad y autoria", Las mujeres y el poder, p. 12.
} 
perjuicio del hijo primogénito del conde, quien tenía el derecho a la herencia del padre. Almodis es, pues, un claro ejemplo de mujer que con autoridad consigue cierto grado de poder.

Otras reinas o condesas, de los distintos reinos peninsulares, tuvieron, como Almodis, una autoridad que se tradujo en poder. Toda de Pamplona, Elvira de León, Ermesinda de Carcasona, Sancha de León, podrian ser buenos ejemplos, aunque la mayoría destaca por su intervención como mediadoras en el reino o condado del que eran titulares. Entre todas estas mujeres de poder, destaca Urraca de Castilla y León, pues ella unió autoridad y poder. Recibió el poder de su padre, y lo ejerció por su capacidad e interés de mantener el reino bajo su propio control. Se la podría calificar de «reina castellana medieval por excelencia»: manda, tiene poder, no es solo influyente, no es simplemente mediadora.

Fuera de estas mujeres, ¿ninguna otra ejerció el poder? Habría que contemplar los campos de actuación de las reinas, para ver si sus funciones les conferían cierto grado de poder, entendiendo como una de las formas de poder, posiblemente la mejor, la capacidad mediadora.

La primera de las funciones de la reina, la función prioritaria, era la de ser la madre de los hijos del rey. Muchas reinas aunque no tuvieran poder, papel o función alguna, eran necesarias precisamente por esa función de ser madres de los hijos legítimos del rey. En el caso de Aragón, eran estrictamente imprescindibles para la transmisión de la potestas, aunque no pudieran ejercerla. Ante estas circunstancias habría que plantearse hasta qué punto aprovecharon ser necesarias para conseguir acceso al poder. El simple hecho de formar parte de la casa del rey, y acompañarle casi siempre les daba la posibilidad de influir en el monarca. Esa influencia la ejercían como mediadoras.

Su capacidad de mediación llegaba, sin embargo, más allá de la simple influencia sobre su marido. La ejercian de forma extraordinaria en casos en que la sucesión planteara problemas especiales, y las reinas madre no tenian inconveniente en luchar a favor del hijo que ellas preferían como heredero, buscando alianzas e intrigando para conseguirlo ${ }^{40}$.

Su posibilidad de influir aumentaba con su capacidad económica, y una de las formas de adquirirla fue mediante el control de propiedades e instituciones de la Iglesia. Esto se encuentra especialmente en los primeros tiempos, durante la monarquía visigoda, en la que las mujeres estuvieron muy inmiscuidas en asuntos religiosos, algo que se ha calificado de "una santidad propia de la realeza" al hablar de las reinas merovingias ${ }^{41}$. También se advierte en los primeros tiempos de consolidación de los reinos, así como

\footnotetext{
to Buen ejemplo de reina madre es Sancha de León y Castilla, cuyos hijos, Sancho II y Alfonso VI, mantuvieron los reinos tal como los habian recibido y no se enfrentaron hasta después de la muerte de la madre

"L. K. LittLe y B. H. Rosenwein (eds.), La Edad Media a debate, p. 379.
} 
en la influencia de las infantas reales, que recibian los monasterios del reino como derecho de infantazgo.

Su relación con la Iglesia se observa también en el importante papel de las mujeres de alcurnia en los movimientos de reforma, tal como aparece en documentos de otros reinos europeos. Buen ejemplo serían las hermanas y esposas de Alfonso VI, quienes colaboraron a la introducción de la reforma de la Iglesia en los reinos de Castilla y León en el siglo XII.

La presencia de las mujeres de la realeza en aspectos bien distintos de la vida del reino, solo permite afirmar que las mujeres no estaban fuera del poder, pero el análisis de su actuación no permite definir con rigor el poder de la reina. Ese "poder extraordinario" que algunos autores no tienen inconveniente en atribuir a las mujeres, ha de tomarse con cautela. Cuando no había una ley restrictiva, las mujeres ejercian el poder, siempre y cuando las circunstancias así lo propiciaran.

El ejercicio del poder político por las mujeres fue excepcional, en la medida en que fueron excepciones las reinas que reunieron en sus manos poder y autoridad; además ese ejercicio del poder fue casi siempre circunstancial, en la medida en que fueron circunstancias especiales las que propiciaron el poder de las reinas. Aunque las circunstancias se podian dar en cualquier tiempo, hubo etapas en las que las mujeres de la realeza gozaron de mayor poder. Esas etapas, siguiendo a P. Stafford, fueron las de conversión (siglo VI) y reforma (siglo $\mathrm{X}$ ) ${ }^{42}$. De la primera etapa se encuentran evidencias en el territorio hispano, de lo contrario no se hubiera encontrado una Goswintha, o no le hubiera sido necesario a Recaredo casarse con Baddo para tener una mujer a su lado en el concilio. También de los tiempos de reforma son buen ejemplo las mujeres citadas en relación con Alfonso VI, aunque no coincidieran en los reinos hispánicos exactamente con el siglo $X$. De ahí que se podría concluir que el poder de la reina no es un poder institucionalizado, sino circunstancial.

Las reinas actuarían en la "casa del rey" con la influencia que otras mujeres influirian en sus casas. La medida de la influencia, de la autoridad, del poder, dependia de muchas circunstancias, pero siempre estaba limitada por las condiciones adversas que padecían las mujeres, con leyes restrictivas de sus derechos. Cuando había varones en la familia tenían que limitarse a influir o a mediar. Se podría concluir que las mujeres han ejercido "otro tipo de poder", la fuerza política de la mediación, que no deja de ser importante poder. Las mujeres de los grupos sociales elevados, y en concreto las mujeres de la realeza tendrian más posibilidades que otras, aunque no es conveniente hacer comparaciones, pues como se ha dicho «las reinas no son mujeres típicas de ninguna época" ${ }^{43}$.

P. STAFFORD, Queens, Concubines and Dowagers, pag. 124.

${ }^{4}$ L. K. LITTLE y B. H. RosenweIn (eds.), La Edad Media a debate, p. 347. 